\title{
Studies of chemical and mechanical properties of hybrid composites based on natural resin Dammar formulated by epoxy resin
}

\section{Heiko Franz ${ }^{1} \cdot$ Ion $\mathrm{Neda}^{2} \cdot$ Catalin V. Maftei ${ }^{2} \cdot$ Ion Ciuca ${ }^{3} \cdot$ Dumitru Bolcu $^{4}$. Marius Marinel Stănescu ${ }^{4}$}

Received: 11 December 2019 / Revised: 14 April 2020 / Accepted: 24 April 2020 / Published online: 6 May 2020 (c) The Author(s) 2020

\begin{abstract}
More and more importance has been given lately to the use of environment-friendly materials. Natural resins of vegetal, animal or mineral origin are increasingly employed. This article studies the properties of hybrid composites, obtained by formulating the natural resin Dammar with epoxy resin. The Dammar volume proportion was of $60 \%, 70 \%$ and $80 \%$, respectively. The article is divided in two parts. In the first part, the chemical composition of the natural resin Dammar is analysed. Therefore, the substance was purified by chromatography. The structure and purity of the isolated substances were investigated by ${ }^{1} \mathrm{H}-\mathrm{NMR},{ }^{13} \mathrm{C}-\mathrm{NMR}$ experiments and mass analysis. The second part concentrates on structural characterization and on some mechanical properties of the three different hybrid composites. For this purpose, the characteristic curves, modulus of elasticity, tensile strength and elongation at break were measured.
\end{abstract}

Electronic supplementary material The online version of this article (https://doi.org/10.1007/s0028 9-020-03221-4) contains supplementary material, which is available to authorized users.

Ion Neda

i.neda@tu-bs.de

1 InnoChemTech GmbH, Hagenring 30, 38106 Brunswick, Germany

2 Institut für Anorganische und Analytische Chemie, Technische Universität Braunschweig, Hagenring 30, 38106 Brunswick, Germany

3 Department of Materials Science and Engineering, University Politehnica of Bucharest, Splaiul Independentei, Nr. 313, 060042 Bucharest, Romania

4 Department of Mechanics, University of Craiova, 165 Calea Bucureşti, 200620 Craiova, Romania 


\section{Graphic abstract}

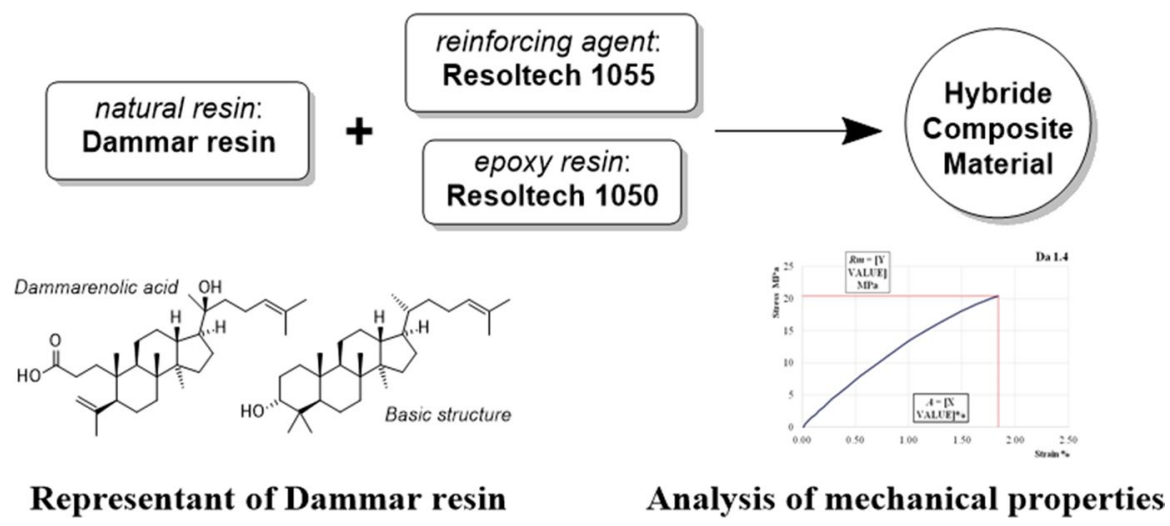

Keywords Dammar resin $\cdot$ Terpenoids $\cdot$ Material science $\cdot$ Natural products

\section{Introduction}

Bio-composite materials have been increasingly used in the last decades, but they have a synthetic resin matrix and show the disadvantage of limited processing, due to their high viscosity when melted, whereas the end product is hard to recycle. These faults can be made up for by resorting to natural resins that can be fossil (Colophony), vegetal (Sandarac, Copal, Dammar), or animal (Shellac). Natural resins cannot be dissolved in water. However, they dissolve in petrol, alcohol and oil. As a consequence, they can be used in combination with organic solvents so as to obtain solutions that may be used as covering lacquers. For example, turpentine, colophony and mastic result from the distillation of certain coniferous resins. Some properties of these resins are to be found in the work of Prati et al. [1]. Suprakas and Mosto [2] present some applications of these resins.

The studies of these resins have mainly focused on their chemical composition and chemical properties and less on their mechanical properties. Thus, RomeroNagueram et al. [3] concentrate in their work on expanding the knowledge about the microbiological bio-deterioration of Dammar-based lacquers in works of art submitted to unsuitable protection conditions, particularly those exposed for a long time to high levels of relative humidity. Zakaria and Ahmad [4] present a new modified binder of silicon and Dammar that reduces the use of synthetic binders and has better and more ecological properties. The work also measures the optimal composition, which ensures the best properties for the impact, hardness, tensile and adherence stresses. Furthermore, Zakaria and Ahmad [5] study in another work the way in which Dammar addition can contribute to improving the rigidity, elasticity modulus and hardness of a modified silicon. 
Dammar gum as additional material to improve thermal conductivity and performance when preparing the composite phase change material was studied [6]. Hamadani et al. [7] investigated the possibility of using beeswax, tallow, and Dammar as PCM (phase change materials) in concrete-made buildings. The effect of polymethyl methacrylate (PMMA) on Dammar's physical properties for the application of covering lacquers was also analysed [8]. The general importance of polymer composites based on epoxy resins is described widely in the work of Hsissou et al. [9, 10]. Because of their many properties which they offer and their ease of handling epoxy resins used to coat materials for their protection [11], mechanical characteristics of composite materials are different and superior to those of the materials used in its composition $[12,13]$.

Nevertheless, there are relatively few studies on the mechanical behaviour of natural resins. Pethe and Joshi [14] researched the mechanical characteristics (tensile strength, percentage elongation and Young's modulus), the characteristics of water vapour transmission, and the dampness absorption characteristics of Dammar films, which contain a softening agent and which do not contain a softening agent. Also, there are few studies on composite materials with both their matrix and reinforcing agent of natural materials. The mechanical behaviour of certain composite materials with a Dammar-based bio-resin matrix, reinforced by cotton, flax, silk and hemp, was examined in the past [15].

\section{Experimental}

\section{General}

All reagents were purchased from commercial sources (Sigma-Aldrich or Acros) and used without further purification. Solvents were of analytical grade. ${ }^{1} \mathrm{H}$ and ${ }^{13} \mathrm{C}$ NMR spectra were recorded at room temperature on a Bruker Avance 300 operating at $400 \mathrm{MHz}$ for ${ }^{1} \mathrm{H}-\mathrm{NMR}$ and $100 \mathrm{MHz}$ for ${ }^{13} \mathrm{C}-\mathrm{NMR}$. Chemical shifts $(\delta)$ are reported relative to the tetramethylsilane peak $(\delta=0.00 \mathrm{ppm})$. Mass spectra were recorded on a Finnigan MAT 8400-MSS and Finnigan MAT 4515. Purifications were monitored by TLC, performed on silica gel plates $40 \times 80 \mathrm{~mm}$ Polygram Sil G। $\mathrm{UV}_{254}$ (Macherey-Nagel). Visualization on TLC was achieved by UV light. Column chromatography was performed with Merck silica gel 60 (70-200 mesh).

\section{Isolation of individual compounds from Dammar resin}

$15 \mathrm{~g}$ of Dammar resin was solved in $100 \mathrm{ml}$ DCM (dichloromethane, or traditional name: methylene dichloride). To this solution was added $50 \mathrm{~g}$ of silica gel. The solvent was removed, and the substance fixed on silica was loaded on a column of silica gel (200 g) and chromatographed using as eluting system n-Hexane-Acetone with a gradient of (20:1-5:1) to give seven fractions (Fr.1-Fr.7). Amounts: Fr1: $1.3 \mathrm{~g}$ colorless oil; Fr2: $0.98 \mathrm{~g}$ white solid; Fr3: $1.6 \mathrm{~g}$ white solid; Fr4: $0.7 \mathrm{~g}$ white solid; Fr5: $0.83 \mathrm{~g}$ white solid; Fr6: $1.03 \mathrm{~g}$ white solid; and Fr7: $1.12 \mathrm{~g}$ white solid. 


\section{Compound 1}

${ }^{13} \mathbf{C}$-NMR $\left(\mathrm{CDCl}_{3}, 100 \mathrm{MHz}\right) \delta 131.55(\mathrm{Cq}), 124.71(\mathrm{CH}), 78.95(\mathrm{CH}), 75.44$ $(\mathrm{Cq}), 55.85(\mathrm{CH}), 50.63(\mathrm{CH}), 50.27(\mathrm{Cq}), 49.82(\mathrm{CH}), 42.26(\mathrm{CH}), 40.48\left(\mathrm{CH}_{2}\right)$, $40.35(\mathrm{Cq}), 39.03\left(\mathrm{CH}_{2}\right), 38.95(\mathrm{Cq}), 35.22\left(\mathrm{CH}_{2}\right), 31.16\left(\mathrm{CH}_{2}\right), 27.98\left(\mathrm{CH}_{3}\right)$, $27.51\left(\mathrm{CH}_{2}\right), 27.37\left(\mathrm{CH}_{2}\right), 25.72\left(\mathrm{CH}_{3}\right), 25.31\left(\mathrm{CH}_{3}\right), 24.79\left(\mathrm{CH}_{2}\right), 23.60(\mathrm{CH})$, $22.53\left(\mathrm{CH}_{2}\right), 21.52\left(\mathrm{CH}_{2}\right), 18.26\left(\mathrm{CH}_{2}\right), 17.69\left(\mathrm{CH}_{3}\right), 16.43\left(\mathrm{CH}_{3}\right), 16.19\left(\mathrm{CH}_{3}\right)$, $15.49\left(\mathrm{CH}_{3}\right), 15.34\left(\mathrm{CH}_{3}\right)$. ${ }^{1} \mathbf{H}-\mathbf{N M R}\left(\mathrm{CDCl}_{3}, 400 \mathrm{MHz}\right) \delta 5.16-5.08(\mathrm{~m}, 1$ $\mathrm{H}) ; 3.20(\mathrm{dd}, J=11.15 \mathrm{~Hz}, J=5.07 \mathrm{~Hz}, 1 \mathrm{H}) ; 2.30-2.15(\mathrm{~m}, 1 \mathrm{H}) ; 2.13-2.1 .78$ $(\mathrm{m}, 4 \mathrm{H}) ; 1.78-1.57(\mathrm{~m}, 3 \mathrm{H}) ; 1.69(\mathrm{~s}, 3 \mathrm{H}) ; 1.62(\mathrm{~s}, 3 \mathrm{H}) ; 1.57-1.38(\mathrm{~m}, 6 \mathrm{H})$; $1.38-1.17(\mathrm{~m}, 4 \mathrm{H}) ; 1.16-0.75(\mathrm{~m}, 8 \mathrm{H}) ; 1.14(\mathrm{~s}, 3 \mathrm{H}) ; 0.97$ (s, $3 \mathrm{H}) ; 0.96$ (s, 3 $\mathrm{H}) ; 0.88(\mathrm{~s}, 3 \mathrm{H}) ; 0.84$ (s, $3 \mathrm{H}) ; 0.77$ (s, $3 \mathrm{H})$. H,H-Cosy, HSQC and HMBC were made. MS(EI) 428 [6], 411 [17], 410 [20], 394 [100]. HRMS(ESI): $\mathrm{m} / \mathrm{z}$ calcd. for $\mathrm{C}_{30} \mathrm{H}_{53} \mathrm{O}_{1}{ }^{+}\left(\mathrm{M}+\mathrm{H}^{+}\right)$429.4091, found 429.4096 .

\section{Compound 7}

M.p.: $140-142{ }^{\circ} \mathrm{C}$. Elem. Anal. Calcd for $\mathrm{C}_{30} \mathrm{H}_{50} \mathrm{O}_{3}(\%)$ : C, 78.55; H, 10.99 . found (\%): C, 78.23; H, 10.87. ${ }^{13} \mathbf{C}-\mathbf{N M R}\left(\mathrm{CDCl}_{3}, 100 \mathrm{MHz}\right) \delta 179.86(\mathrm{Cq})$, $147.42(\mathrm{Cq}), 131.59(\mathrm{Cq}), 124.61(\mathrm{CH}), 113.43\left(\mathrm{CH}_{2}\right), 75.60(\mathrm{Cq}), 50.76(\mathrm{CH})$, $50.64(\mathrm{Cq}), 49.44(\mathrm{CH}), 42.30(\mathrm{CH}), 40.99(\mathrm{CH}), 40.56\left(\mathrm{CH}_{2}\right), 40.00(\mathrm{Cq}), 39.01$ $(\mathrm{Cq}), 34.24\left(\mathrm{CH}_{2}\right), 33.80\left(\mathrm{CH}_{2}\right), 31.18\left(\mathrm{CH}_{2}\right), 28.32\left(\mathrm{CH}_{2}\right), 37.40\left(\mathrm{CH}_{2}\right), 25.71$ $\left(\mathrm{CH}_{3}\right), 25.29\left(\mathrm{CH}_{3}\right), 24.74\left(\mathrm{CH}_{2}\right), 24.58\left(\mathrm{CH}_{2}\right), 23.19\left(\mathrm{CH}_{3}\right), 22.52\left(\mathrm{CH}_{2}\right), 22.03$ $\left(\mathrm{CH}_{2}\right), 20.12\left(\mathrm{CH}_{3}\right), 17.69\left(\mathrm{CH}_{3}\right), 16.34\left(\mathrm{CH}_{3}\right), 15.30\left(\mathrm{CH}_{3}\right) .{ }^{1} \mathbf{H}-\mathbf{N M R}\left(\mathrm{CDCl}_{3}\right.$, $400 \mathrm{MHz}) \delta 5.12(\mathrm{t}, J=1.28 \mathrm{~Hz}, 1 \mathrm{H}) ; 4.85(\mathrm{~s}, 1 \mathrm{H}) ; 4.66(\mathrm{~s}, 1 \mathrm{H}) ; 2.45-2.31(\mathrm{~m}$, $1 \mathrm{H}) ; 2.25-2.13(\mathrm{~m}, 1 \mathrm{H}) ; 2.10-1.92(\mathrm{~m}, 3 \mathrm{H}) ; 1.90-1.57(\mathrm{~m}, 6 \mathrm{H}) ; 1.73(\mathrm{~s}, 3 \mathrm{H})$; $1.69(\mathrm{~s}, 3 \mathrm{H}) ; 1.63(\mathrm{~s}, 3 \mathrm{H}) ; 1.57-1.36(\mathrm{~m}, 7 \mathrm{H}) ; 1.36-1.19$ (m, $3 \mathrm{H}) ; 1.18-1.03$ $(\mathrm{m}, 2 \mathrm{H}) ; 1.15(\mathrm{~s}, 3 \mathrm{H}) ; 1.00(\mathrm{~s}, 3 \mathrm{H}) ; 0.98-0.82(\mathrm{~m}, 1 \mathrm{H}) ; 0.89(\mathrm{~s}, 3 \mathrm{H}) ; 0.85$ (s, 3 H). H,H-Cosy, HSQC and HMBC were made. MS(EI) 458 [3], 440 [25], 424 [100]. HRMS (ESI): $m / z$ calcd. for $\mathrm{C}_{30} \mathrm{H}_{50} \mathrm{Na}_{1} \mathrm{O}_{3}\left(\mathrm{M}+\mathrm{Na}^{+}\right) 481.3652$, found 481.3658 .

\section{Compound 8}

Elem. Anal. Calcd for $\mathrm{C}_{30} \mathrm{H}_{46} \mathrm{O}_{3}(\%)$ : C, 79.25; H, 10.20. found (\%): C, 79.13; $\mathrm{H}$, 10.05. ${ }^{13} \mathrm{C}-\mathrm{NMR}\left(\mathrm{CDCl}_{3}, 100 \mathrm{MHz}\right) \delta 217.74(\mathrm{Cq}), 207.27(\mathrm{CH}), 137.93(\mathrm{Cq})$, $125.91(\mathrm{CH}), 55.23(\mathrm{CH}), 52.63(\mathrm{CH}), 50.17(\mathrm{Cq}), 47.37(\mathrm{Cq}), 46.76(\mathrm{CH}), 45.53$ $\left(\mathrm{CH}_{2}\right), 42.27(\mathrm{Cq}), 39.77(\mathrm{Cq}), 39.35\left(\mathrm{CH}_{2}\right), 38.81(\mathrm{CH}), 36.62(\mathrm{Cq}), 34.14\left(\mathrm{CH}_{2}\right)$, $32.62\left(\mathrm{CH}_{2}\right), 31.80\left(\mathrm{CH}_{2}\right), 30.14\left(\mathrm{CH}_{2}\right), 26.84\left(\mathrm{CH}_{2}\right), 26.58(\mathrm{CH}), 26.44\left(\mathrm{CH}_{3}\right)$, $23.45\left(\mathrm{CH}_{2}\right), 23.16\left(\mathrm{CH}_{2}\right), 23.12\left(\mathrm{CH}_{3}\right), 21.46(\mathrm{CH}), 21.03\left(\mathrm{CH}_{3}\right), 19.54\left(\mathrm{CH}_{2}\right)$, $16.95\left(\mathrm{CH}_{3}\right), 15.29\left(\mathrm{CH}_{3}\right) .{ }^{\mathbf{1}} \mathbf{H}-\mathbf{N M R}\left(\mathrm{CDCl}_{3}, 400 \mathrm{MHz}\right) \delta 9.33(\mathrm{~s}, 1 \mathrm{H}) ; 5.48-5.42$ $(\mathrm{m}, 1 \mathrm{H}) ; 5.36-5.32(\mathrm{~m}, 1 \mathrm{H}) ; 2.60-2.47(\mathrm{~m}, 2 \mathrm{H}) ; 2.44-2.31(\mathrm{~m}, 2 \mathrm{H}) ; 2.25-1.80$ $(\mathrm{m}, 4 \mathrm{H}) ; 1.79-1.20(\mathrm{~m}, 8 \mathrm{H}) ; 1.20-1.0 .72(\mathrm{~m}, 10 \mathrm{H}) ; 1.10(\mathrm{~s}, 3 \mathrm{H}) ; 1.04(\mathrm{~s}, 3 \mathrm{H})$; 0.97 (s, $3 \mathrm{H}) ; 0.95$ (s, $3 \mathrm{H}) ; 0.94$ (s, $3 \mathrm{H})$; 0.92 (s, $3 \mathrm{H})$. H,H-Cosy, HSQC and 
HMBC were made. MS(EI) 456 [3], 438 [29], 409 [100]. HRMS (ESI): $\mathrm{m} / \mathrm{z}$ calcd. for $\mathrm{C}_{30} \mathrm{H}_{46} \mathrm{Na}_{1} \mathrm{O}_{3}\left(\mathrm{M}+\mathrm{Na}^{+}\right) 477.3339$, found 477.3331 .

\section{Compound 9}

Elem. Anal. Calcd for $\mathrm{C}_{30} \mathrm{H}_{44} \mathrm{O}_{3}(\%)$ : C, 79.60; H, 9.80. found (\%): C, 79.42; $\mathrm{H}$, 9.65. ${ }^{13} \mathrm{C}-\mathrm{NMR}\left(\mathrm{CDCl}_{3}, 100 \mathrm{MHz}\right) \delta 217.69(\mathrm{Cq}), 207.34(\mathrm{CH}), 143.04(\mathrm{Cq})$, $122.98(\mathrm{CH}), 55.29(\mathrm{CH}), 49.10(\mathrm{Cq}), 47.41(\mathrm{Cq}), 46.78(\mathrm{CH}), 41.81(\mathrm{Cq}), 40.43$ $(\mathrm{CH}), 39.53(\mathrm{Cq}), 39.16\left(\mathrm{CH}_{2}\right), 38.96(\mathrm{CH}), 36.70(\mathrm{Cq}), 34.12\left(\mathrm{CH}_{2}\right), 33.13\left(\mathrm{CH}_{2}\right)$, $33.03(\mathrm{CH}), 31.26\left(\mathrm{CH}_{2}\right), 30.62(\mathrm{Cq}), 27.68\left(\mathrm{CH}_{2}\right), 26.71\left(\mathrm{CH}_{2}\right), 25.40\left(\mathrm{CH}_{3}\right), 23.50$ $\left(\mathrm{CH}_{2}\right), 23.39\left(\mathrm{CH}_{3}\right), 22.04\left(\mathrm{CH}_{2}\right), 21.44\left(\mathrm{CH}_{3}\right), 19.54\left(\mathrm{CH}_{2}\right), 17.18\left(\mathrm{CH}_{3}\right), 15.64$ $\left(\mathrm{CH}_{3}\right), 15.04\left(\mathrm{CH}_{3}\right)$.

${ }^{1} \mathbf{H}-\mathbf{N M R}\left(\mathrm{CDCl}_{3}, 400 \mathrm{MHz}\right) \delta 9.40(\mathrm{~s}, 1 \mathrm{H}) ; 5.52-5.48(\mathrm{~m}, 1 \mathrm{H}) ; 5.39-5.35(\mathrm{~m}$, $1 \mathrm{H})$; 2.69-2.61 (m, $1 \mathrm{H}) ; 2.60-2.47(\mathrm{~m}, 1 \mathrm{H}) ; 2.44-2.31(\mathrm{~m}, 2 \mathrm{H}) ; 2.25-1.80$ (m, $4 \mathrm{H})$; 1.79-1.20 (m, $7 \mathrm{H}) ; 1.20-1.0 .72(\mathrm{~m}, 8 \mathrm{H}) ; 1.15(\mathrm{~s}, 3 \mathrm{H}) ; 1.09$ (s, $3 \mathrm{H}) ; 0.99$ (s, $3 \mathrm{H}) ; 0.96(\mathrm{~s}, 3 \mathrm{H}) ; 0.91(\mathrm{~s}, 3 \mathrm{H}) ; 0.88$ (s, $3 \mathrm{H})$. H,H-Cosy, HSQC and HMBC were made. MS(EI) 454 [3], 436 [23], 407 [100]. HRMS (ESI): $\mathrm{m} / z$ calcd. for $\mathrm{C}_{30} \mathrm{H}_{44} \mathrm{Na}_{1} \mathrm{O}_{3}{ }^{+}\left(\mathrm{M}+\mathrm{Na}^{+}\right)$475.3183, found 475.3179.

\section{Infrared spectroscopy}

Bruker ${ }^{\mathrm{TM}}$ Fourier transformed infrared spectrometer is used for recording the infrared spectra. The light beam passes through the sample. The thickness of the sample is $2 \mu \mathrm{m}$. The analysis is carried out between 4000 and $600 \mathrm{~cm}^{-1}$.

\section{Hybrid composites}

The natural resin Dammar, diluted by turpentine, hardens in time if it is applied in thin layers. If kept in containers, it remains liquid. The composite materials based only on this resin have a very long hardening time. To remove this shortcoming, it is sufficient that this resin should be combined with synthetic resins.

We cast three bio-resin plates, where we used Dammar with a volume proportion of 60\% (Da 1), 70\% (Da 2) and 80\% (Da 3). The difference up to 100\% consisted of Resoltech 1050 epoxy resin, together with its associated reinforcing agent Resoltech 1055. The synthetic component (epoxy resin and reinforcing agent) was necessary for generating quick activation points of the polymerization process. The temperature ranged between 21 and $23{ }^{\circ} \mathrm{C}$. We observed the producer's indications to make the combination of Resoltech 1050 and the reinforcer Resoltech 1055. We used a mixture of $7 / 3$ volume proportion. We mixed the obtained epoxy resin with Dammar resin. All samples of the three types of hybrid composite were cut out after 10 days.

We cut three sets of ten samples out of the cast plates, labelled Da 1.1-10, Da 2.1-10, Da 3.1-10. The size of the samples was $250 \mathrm{~mm}$ long and $25 \mathrm{~mm}$ wide, according to ASTM D3039. The thickness was $6.1 \mathrm{~mm}$ for the samples of the Da 1.X and Da 2.X sets and $6.0 \mathrm{~mm}$ for the samples of the Da 3.X set. The sample density ranged between 1.04 and $1.06 \mathrm{~g} / \mathrm{cm}^{3}$. 


\section{Results and discussion}

\section{Identification of single compounds in Dammar resin}

A Dammar resin was purified by column chromatography, and the isolated substances were investigated by NMR experiment and mass analysis. In the past Hidayat et al. [16] analysed the Dammar resin from Aglaia elliptica. They described six compounds which were isolated for the first time in this plant (Fig. 1). Further results are given in [17].

By chromatographic purification, we obtained seven fractions from which four contained a single compound. These were fractions three, four, six and seven. The others contained mixtures. For the determination of the structure, the pure substances were analysed mainly by ${ }^{1} \mathrm{H}-\mathrm{NMR}$ and ${ }^{13} \mathrm{C}-\mathrm{NMR}$ experiments and mass and elemental analysis.<smiles>CC(C)=CCC[C@H](C)[C@H]1CC[C@H]2[C@@H]1CC[C@H]1[C@@]2(C)CC[C@H]2C(C)(C)[C@@H](O)CC[C@]12C</smiles>

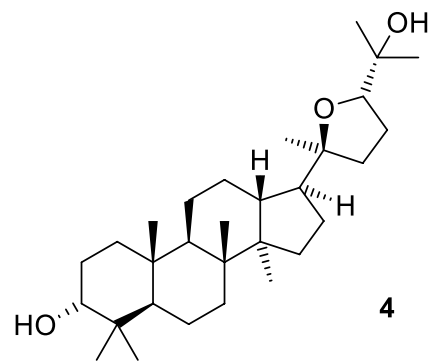

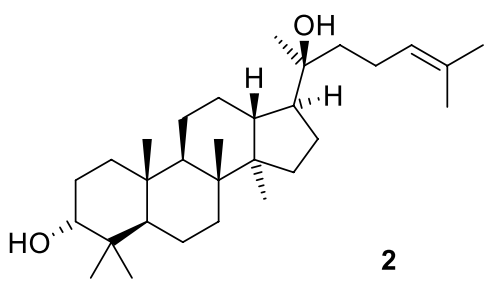

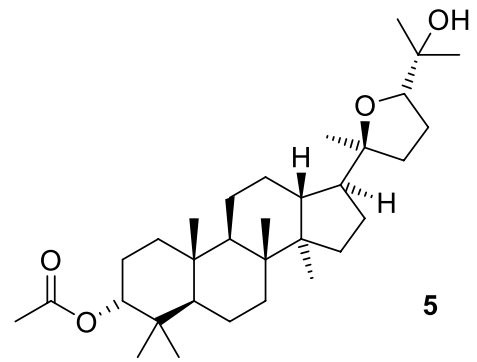<smiles>C[C@H](C/C=C/C(C)(C)O)[C@H]1CC[C@H]2[C@@]3(C)CC[C@H]4C(C)(C)[C@@H](O)CC[C@]4(C)[C@H]3CC[C@]12C</smiles>

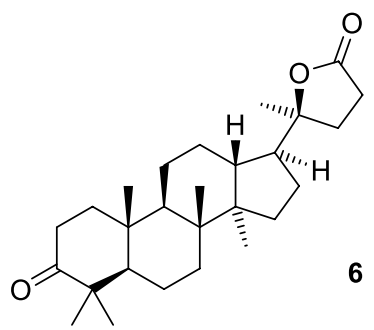

Fig. 1 For comparison: identified compounds from Hidayat et al. [16] 
Fig. 2 Structure of Dammarenolic acid 7 from fraction 7<smiles>C=C(C)[C@H]1CC[C@]2(C)[C@@H](CC[C@H]3[C@@H]([C@](C)(O)CCC=C(C)C)CC[C@]32C)[C@@]1(C)CCC(=O)O</smiles>

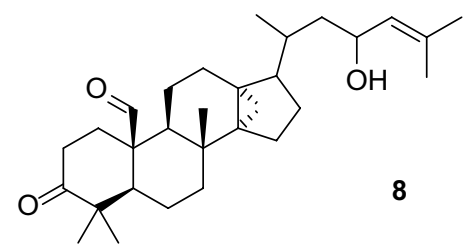

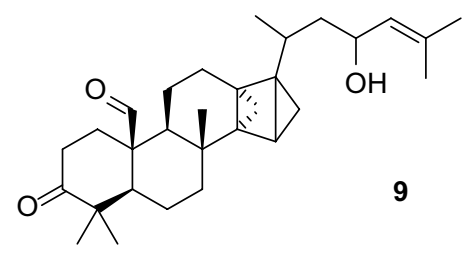

Fig. 3 Structures of compound $\mathbf{8}$ from fraction 3 and compound 9 from fraction 4

The already known $(5 \mathrm{R}, 8 \mathrm{R}, 9 \mathrm{R}, 10 \mathrm{R}, 13 \mathrm{R}, 14 \mathrm{R}, 17 \mathrm{R})-4,4,8,10,14$-pentamethyl17-((R)-6-methylhept-5-en-2-yl)hexadecahydro-1H-cyclo-penta[a]phenanthren-3-ol (1) was identified in fraction six as a component of the Dammar resin mixture investigated. This is not surprising as this compound is the basic structure of the Dammar material class. It was described, among others, by the already mentioned group of Hidayat [16].

The substance in fraction 7 could be identified as 3-((3S,3aR,5aR,5aR,5aR,6S,7S,9aR,9bR)-3-((S)-2-hydroxy-6-methylhept-5-en-2yl)-6,9a,9b-trimethyl-7-(prop-1-en-2-yl)dodecahydro-1H-cyclo-penta[a]naphthalin-6-yl)propionic acid (7). The structure is an interesting secondary metabolite in which ring A was opened from the Dammar skeleton generating a carboxylic acid functionality by oxidation of the secondary alcohol at C-3 under C-C-bond breakage (Fig. 2). Compound 7 is also known as Dammarenolic acid [18].

In fraction 3 and 4 two interesting substances could be identified (Fig. 3) as (5R,8R,9S, 10S, 13R, 14R)-17-(4-hydroxy-6-methylhept-5-en-2-yl)-4,4,8-trimethyl3-oxododecahydro-15H-13,14-methanocyclopenta[a] phenanthrene-10(1H)-carbaldehyde (8) and (4aS,4bS,6aR,7bS,7cR,9aR)-6b-(4-hydroxy-6-methylhept-5-en2-yl)-1,1,7c-trimethyl-2-oxo-dodeca-hydro-7H-6a,7b-methanocyclopropa[3,4] cyclobuta[1,2-a]phenanthrene-4a( $2 H)$-carb-aldehyde (9). Both show similar modifications. On the one hand, the hydroxy group at position three was oxidized to ketone in a known manner. Secondly, more interestingly, a methyl group was converted into an aldehyde function. To the best of our knowledge, this combination of aldehyde and ketone is unique in Dammar's substance class. Although these substances are strongly oxidized in ring $\mathrm{A}$, the prenyl group in the side chain is still intact. The establishment of a cyclopropyl ring is also interesting. How this functionality is formed has not yet been clarified in this work. In total, aldehydes $\mathbf{8}$ and $\mathbf{9}$ show interesting structural changes compared to the Dammar strain system, which is represented by compound $\mathbf{1}$. 


\section{Structural characterization by IR spectroscopy}

After the synthesis of the composite materials, we proceeded to the structural identification of the latter by Fourier transformed infrared spectroscopy. As an example, the IR spectrum of the hybrid composite material Da 2.5 is given in Fig. 4. The allocation of different bands of the material is the following. The band at $3341 \mathrm{~cm}^{-1}$ represents the different types of hydroxy groups. Aliphatic methylene bond elongation is represented by the two bands at $2922 \mathrm{~cm}^{-1}$ and $2852 \mathrm{~cm}^{-1}$. At last, should be mentioned the band at $1032 \mathrm{~cm}^{-1}$ which is formed by variation of binding valence of aliphatic ethers $\left(\mathrm{CH}_{2}-\mathrm{O}\right)$. Since the IR spectra of the compounds from the Dammar resin are also dominated by the bands belonging to the aliphatic methylene groups, the differences between the different IR spectra of the different types of hybrid composite materials are small.

\section{Mechanical properties}

The bio-resin samples underwent a tensile test, which was carried out according to the ASTM D3039 provisions [19]. We used the LRX Plus testing machine from LLOYD Instruments with the following specifications: Force range: $2.5 \mathrm{kN}$; Travel: 1-735 mm; Crosshead speed: 0.1-500 mm/min; Analysis software: NEXYGEN.

The elements obtained from this trial were: the characteristic curve, tensile strength $R_{m}(\mathrm{MPa})$, percentage elongation after fracture $A(\%)$ and elasticity modulus $E\left(\mathrm{~N} / \mathrm{mm}^{2}\right)$.

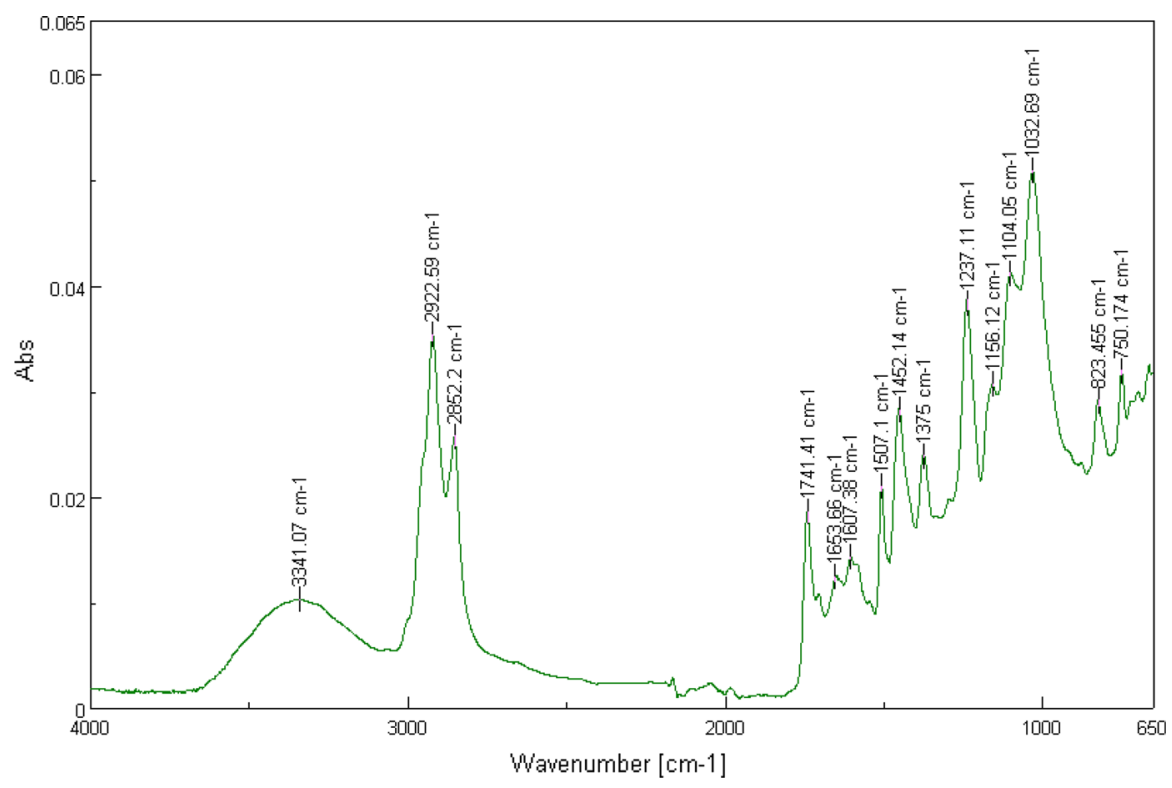

Fig. 4 IR spectrum of a composite material containing 30\% epoxy resin and 70\% Dammar (DA 2.5) 


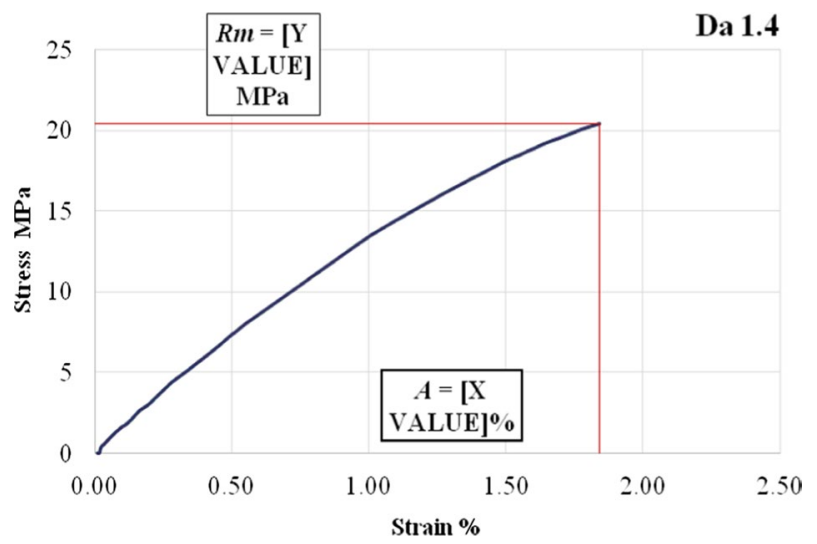

Fig. 5 The characteristic curve for a Da 1.X set representative sample

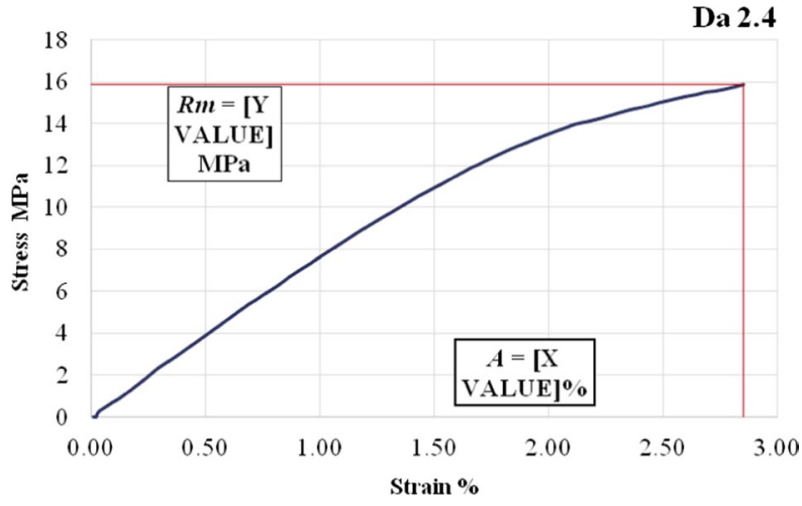

Fig. 6 The characteristic curve for a Da 2.X set representative sample

Henceforward, by representative sample we understand the sample with the average values of the studied mechanical properties. The characteristic curves of the representative samples of the three sets of hybrid composites are presented in Figs. 5, 6 and 7.

Table 1 shows the value limits of the tensile strength, modulus of elasticity and elongation at break for the three types of hybrid composites that have been studied.

\section{Conclusion}

The use of natural resins for manufacturing composite materials can be influenced by the resin properties and the capacity of producing a synergetic effect together with the reinforcing materials. The analysis of the obtained results shows an important variation of the properties, depending on the proportion between natural and synthetic resin. 


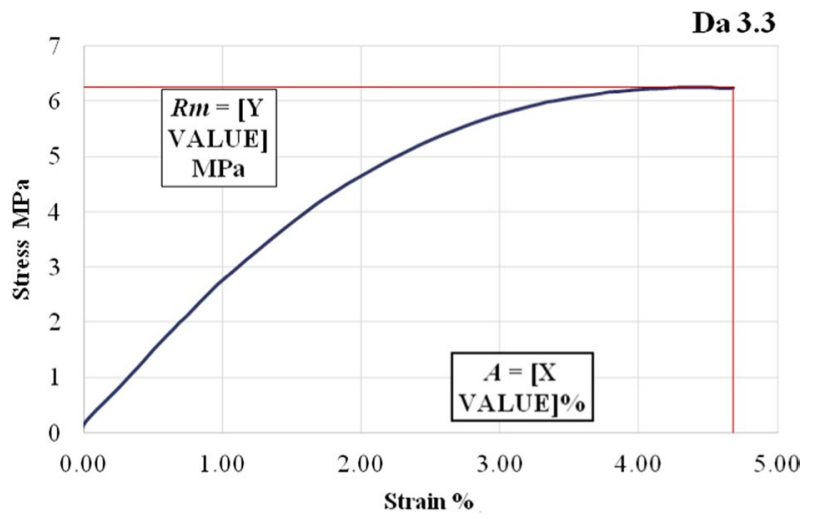

Fig. 7 The characteristic curve for a Da 3.X set representative sample

Table 1 Value limits of tensile strength, elasticity modulus and elongation at break

\begin{tabular}{lcll}
\hline Sample & $\begin{array}{l}\text { Tensile strength } \\
p /(\mathrm{MPa})\end{array}$ & $\begin{array}{l}\text { Elasticity modulus } \\
p /(\mathrm{MPa})\end{array}$ & $\begin{array}{l}\text { Elongation } \\
\text { at break } \\
(\%)\end{array}$ \\
\hline Da 1X & $20.2-21.4$ & $4990-5690$ & $1.82-2.02$ \\
$\mathrm{Da} 2 \mathrm{X}$ & $15.3-16.3$ & $2100-2410$ & $2.83-2.98$ \\
$\mathrm{Da} 3 \mathrm{X}$ & $6.2-6.6$ & $860-950$ & $4.45-4.83$ \\
\hline
\end{tabular}

Comparing the experimental results points out an important modification of the mechanical properties when changing the proportion of epoxy resin and natural resins. There is a decrease in the values of the tensile strength, and the modulus of elasticity as the volume proportion of the natural resins is being increased in the mixture. Although the mixtures with a higher amount of epoxy resin have better mechanical properties, we cannot say that there is a certain proportionality between the tensile strength, or the modulus of elasticity, and the volume proportion of epoxy resin. Thus, the 60\% Dammar mixture (Da 1) has the best values of mechanical properties. Compared to this, the 70\% Dammar mixture (Da 2) has a $76 \%$ tensile strength and its modulus of elasticity is $42 \%$, while the $80 \%$ Dammar mixture (Da 3 ) has a $31 \%$ tensile strength and a modulus of elasticity of $17 \%$. We notice a significant reduction in the mechanical properties as the Dammar percentage in the mixture is being increased.

There are modifications concerning the forms of the characteristic curves. If the characteristic curve is almost linear in the resins Da 1 , where the natural resin proportion is $60 \%$, there is an obvious nonlinearity of the characteristic curve of the Da 3 resins, where the natural resin proportion is $80 \%$. In these cases, it is evident that there is a plastic behaviour.

We notice that there an increase in the elongation at break as the Dammar proportion is increased. 
An increase of $80 \%$ in the Dammar proportion results both in a decline of the mechanical properties and an increase in the hardening time, up to values that are not recommended for manufacturing composite materials.

The fact that the properties of the Dammar-based hybrid composites can be modified, depending on the proportion of natural and synthetic resin, could be used so as to keep under control the mechanical properties of the composite materials based on these resins.

\section{Acknowledgement Open Access funding provided by Projekt DEAL.}

Open Access This article is licensed under a Creative Commons Attribution 4.0 International License, which permits use, sharing, adaptation, distribution and reproduction in any medium or format, as long as you give appropriate credit to the original author(s) and the source, provide a link to the Creative Commons licence, and indicate if changes were made. The images or other third party material in this article are included in the article's Creative Commons licence, unless indicated otherwise in a credit line to the material. If material is not included in the article's Creative Commons licence and your intended use is not permitted by statutory regulation or exceeds the permitted use, you will need to obtain permission directly from the copyright holder. To view a copy of this licence, visit http://creativecommons.org/licen ses/by/4.0/.

\section{References}

1. Prati S, Sciutto G, Mazzeo R, Torri C, Fabbri D (2011) Application of ATR-far-infrared spectroscopy to the analysis of natural resins. Anal Bioanal Chem 399:3081-3091

2. Suprakas SR, Mosto B (2005) Biodegradable polymers and their layered silicate nanocomposites: in greening the 21st century materials world. Prog Mater Sci 50:962-1079

3. Romero-Nogueram J, Martín-Sánchez I, López-Miras MM, Ramos-López JM, Bolívar-Galiano F (2010) Biodeterioration patterns found in Dammar resin used as art material. Electron J Biotechnol $13: 1-8$

4. Zakaria R, Ahmad AH (2012) Adhesion and hardness evaluation of modified silicone-Dammar as natural coating materials. Am J Appl Sci 9:890-893

5. Zakaria R, Ahmad AH (2012) The performance of modified silicone-Dammar resin in nanoindentation test. Int J Adv Sci Technol 42:33-44

6. Fauzi H, Metselaar HSC, Mahlia TMI, Ong HC, Khanlou HM (2016) Preparation and thermal characteristics of eutectic fatty acids/Shorea javanica composite for thermal energy storage. Appl Therm Eng 100:62-67

7. Hamdani Rizal S, Riza M, Mahlia TMI (2018) Mechanical properties of concrete containing beeswax/Dammar gum as phase change material for thermal energy storage. AIMS Energy 6:521-529

8. Nasir KM, Halim NA, Tajuddin HA, Arof AK, Abidin ZHZ (2013) The effect of PMMA on physical properties of Dammar for coating paint application. Pigm Resin Technol 42:137-145

9. Hsissou R, About S, Berisha A, Berradi M, Assouag M, Hajjaji N, Elharfi A (2019) Experimental, DFT and molecular dynamics simulation on the inhibition performance of the DGDCBA epoxy polymer against the corrosion of the E24 carbon steel in $1.0 \mathrm{M} \mathrm{HCl}$ solution. J Mol Struct 1182:340-351

10. Hsissou R, Dagdag O, Berradi M, El Bouchti M, Assouag M, Elharfi A (2019) Development rheological and anti-corrosion property of epoxy polymer and its composite. Heliyon 5:e02789

11. Hsissou R, El Bouchti M, El Harfi A (2017) Elaboration and viscosimetric, viscoelastic and rheological studies of a new hexafunctional polyepoxide polymer: hexaglycidyl ethylene of methylene dianiline. J Mater Environ Sci 8:4349-4361

12. Hsissou R, Elharfi A (2018) Rheological behavior of three polymers and their hybrid composites (TGEEBA/MDA/PN), (HGEMDA/MDA/PN) and (NGHPBAE/MDA/PN). J King Saud Univ Sci $32: 235-244$ 
13. Hsissou R, Berradi M, El Bouchti M, El Bachiri A, El Harfi A (2019) Synthesis characterization rheological and morphological study of a new epoxy resin pentaglycidyl ether pentaphenoxy of phosphorus and their composite (PGEPPP/MDA/PN). Polym Bull 76:4859-4878

14. Pethe AM, Joshi SB (2013) Physicomedical, mechanical and film forming studies of novel biomaterial. Int J Pharm Sci Res 4:2761-2769

15. Ciucă I, Bolcu A, Stănescu MM (2017) A study of some mechanical properties of bio-composite materials with a Dammar-based matrix. Environ Eng Manag J 16:2851-2856

16. Hidayat AT, Farabi K, Harneti D, Maharani R, Darwati N, Mayanti T, Setiawan AS, Supratman U, Shiono Y (2017) Cytotoxicity and structure activity relationship of dammarane-type triterpenoids from the bark of Aglaia elliptica against P-388 murine leukemia cells. Nat Prod Sci 23:291-298

17. Zhang F, Wang JS, Gu YC, Kong LY (2010) Triterpenoids from Aglaia abbreviata and their cytotoxic activities. J Nat Prod 73:2042-2046

18. Ukiya M, Kikuchi T, Tokunda H, Tabata K, Kimura Y, Arai T, Ezaki Y, Oseto O, Suzuki T, Akihisa $\mathrm{T}$ (2010) Antitumor-promoting effects and cytotoxic activities of Dammar resin triterpenoids and their derivatives. Chem Divers 7:1871-1884

19. ASTM D3039, Standard test method for tensile properties of polymer matrix composite materials. https://www.astm.org/Standards/D3039. Accessed on 9 Jan 2019

Publisher's Note Springer Nature remains neutral with regard to jurisdictional claims in published maps and institutional affiliations. 